This item was submitted to Loughborough's Research Repository by the author.

Items in Figshare are protected by copyright, with all rights reserved, unless otherwise indicated.

\title{
Effect of clutch lining frictional characteristics on take-up judder
}

PLEASE CITE THE PUBLISHED VERSION

http://dx.doi.org/10.1177/1464419317708946

PUBLISHER

Sage $\odot$ IMechE

VERSION

AM (Accepted Manuscript)

PUBLISHER STATEMENT

This work is made available according to the conditions of the Creative Commons Attribution-NonCommercialNoDerivatives 4.0 International (CC BY-NC-ND 4.0) licence. Full details of this licence are available at: https://creativecommons.org/licenses/by-nc-nd/4.0/

\section{LICENCE}

CC BY-NC-ND 4.0

\section{REPOSITORY RECORD}

Gkinis, Theofilos, Ramin Rahmani, and Homer Rahnejat. 2019. "Effect of Clutch Lining Frictional Characteristics on Take-up Judder”. figshare. https://hdl.handle.net/2134/25206. 
Proceedings of the Institution of Mechanical Engineers, Part K: Journal of Multibody

Dynamics, May 2017, DOI: 10.1177/1464419317708946 (Accepted Version)

\title{
Effect of clutch lining frictional characteristics on take-up judder
}

\author{
T. Gkinis, R. Rahmani ${ }^{*}$, H. Rahnejat \\ Wolfson School of Mechanical, Electrical and Manufacturing Engineering, Loughborough \\ University, Leicestershire, UK \\ *Corresponding Author: R.Rahmani@lboro.ac.uk
}

\begin{abstract}
Take-up judder is the first rigid body torsional mode of the clutch system, which occurs during clutch engagement. This phenomenon is induced by stick-slip oscillations at the friction lining interfaces between the clutch disc and flywheel, and the pressure plate. The phenomenon is influenced by the clutch lining friction characteristics, the topography of the mating-sliding surfaces and the operational conditions during the engagement process. Therefore, the interfacial characteristics are affected by contact pressure, interfacial slip speed and surface temperature. Take-up judder causes driver and vehicle occupant discomfort, as well as gradual wear of contacting surfaces. The response frequency of the system is reported to be in the range $5-20 \mathrm{~Hz}$, depending on the clutch system and vehicle inertia.

In this paper the measured interfacial friction characteristics together with clamp load variation (contact pressure) under different surface temperatures are included in a multidegree of freedom dynamic analysis to obtain torsional vibrations of the system, pertaining to take-up judder conditions. Such an in-depth investigation has not hitherto been reported in literature. The paper shows that take-up judder is omnipresent under all clutch engagement conditions, but its poignancy is most evident at cold surface temperatures. It is also shown that the transient judder response has a broader spectral content that is generally acknowledged.
\end{abstract}

Keywords: Dry automotive clutch; Torsional vibrations; Take-up judder; Stick-slip oscillations; Friction lining characteristics

\section{Nomenclature}

A Effective vehicle frontal area

a Wavelet scaling parameter

b Position parameter

C Damping matrix

c Damping coefficient

$C_{d} \quad$ Aerodynamic drag coefficient

$d_{\text {air } \quad \text { Density of air }}$ 


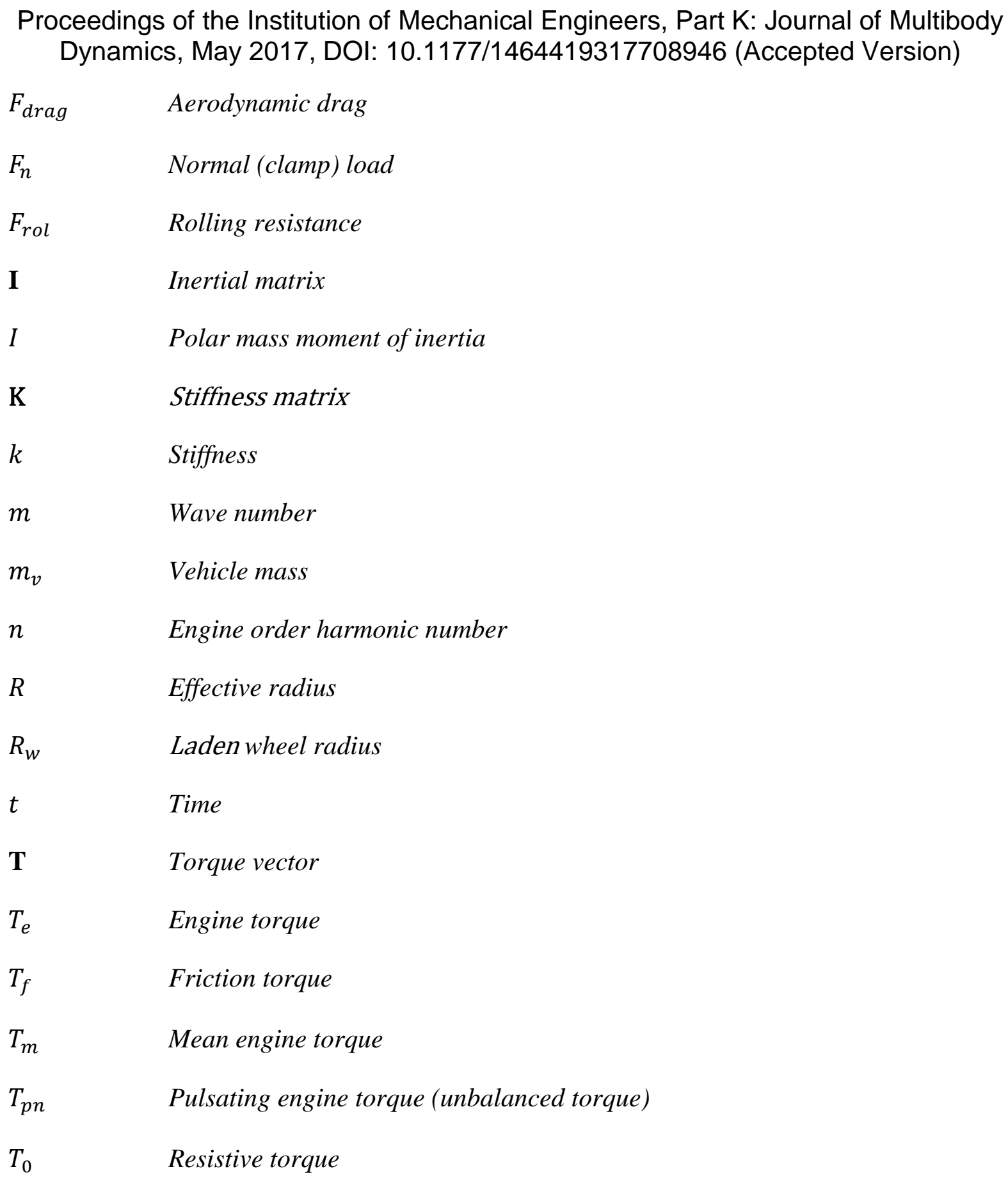




$\begin{aligned} & \text { Proceedings of the Institution of Mechanical Engineers, Part K: Journal of Multibody } \\ & \text { Dynamics, May 2017, DOI: 10.1177/1464419317708946 (Accepted Version) }\end{aligned}$
$\begin{array}{ll}\mu_{\text {rol }} & \text { Coefficient of rolling resistance } \\ \varphi_{p n} & \text { Initial phase of the } \text { nth engine order } \\ \psi & \text { Mother wavelet function } \\ \omega_{\iota} & \text { Angular velocity } \\ \omega_{n} & \text { Natural frequency }\end{array}$

\section{Abbreviations}

CWT Continue wavelet transform

DOF Degrees of freedom

\section{Introduction}

Take-up judder is the first rigid body low frequency $(5-20 \mathrm{~Hz})$ torsional mode of the clutch system which can occur during clutch engagement [1]. During clutch engagement the speed of the driver (engine) reduces whilst that of the driven (the drive train) increases such that ideally a unison speed is reached. There are some oscillatory responses of both the driver and the driven during this process. These oscillations are caused by stick-slipping at the clutch friction lining interfaces with the flywheel and/or the pressure plate [2]. Jarvis and Mills [3] presented clutch judder as a vibration, primarily induced by friction in dry clutches. However, this phenomenon is not only confined to dry clutches as shown by Berglund et al [4]. Centea et al [5-6] showed that clutch take-up judder is influenced by the gradient of coefficient of friction variation with the relative speed at the clutch lining interfaces (i.e. the $\mu-v$ characteristics). They showed that a negative slope characteristic promotes the propensity to judder with a greater degree of severity. This is discernible by the vehicle occupants [5-8]. Another cause of take-up judder is loss of clamp load with hurried release of clutch pedal [5$6,8]$.

Engine torque fluctuations also affect clutch judder vibrations, which has been investigated by several authors [9-10]. They have shown that judder vibrations are exacerbated when the engine angular velocity harmonics coincide with the natural frequency of the clutch system. Rabieh and Crolla [10] investigated the coupling of clutch torsional vibration with the fore and aft longitudinal oscillations of the vehicle, termed as shunt. This effect occurs during the clutch engagement and is distinct from the more generally accepted definition of the shunt phenomenon. This is as the result of throttle tip-in or back-out actions or a sudden release of the clutch pedal with the vehicle in motion [11]. Shunt is often coupled with first rigid body mode of the entire driveline system, known as shuffle, which is at a lower frequency than clutch judder.

Heat is generated in the clutch interfacial contacts due to friction, often in a localised manner, referred to as hot spotting [8], causing uneven thermal deformation of the clutch friction disc. This effect exacerbates stick-slip vibrations and is generally termed as hot judder, which is 
more discernible in brake systems [12]. Panier et al [13] experimentally investigated hot spotting in train disc brakes, using a full-scale rig. It was determined that the main cause of hot spotting was the gradual distortion of the surface waviness due to high thermal loading. Graf and Ostemeyer [14] studied the effect of material thermal properties such as thermal conductivity, thermal diffusivity and wear on the formation of hot spots. It was found that in order to reduce the formation of hot spots, thermal conductivity needs to be decreased or alternatively increase thermal diffusivity.

Pin-on-disc tribometry is often used to obtain frictional characteristics of clutch/brake lining materials at different applied pressures, sliding velocities and bulk surface temperatures. Ost et al [15] used a pin-on-disc tribometer to study the frictional characteristics of paper-based friction material used in wet clutches. They concluded that the kinetic coefficient of friction increases with decreasing contact pressure, but reduces with an increased sliding velocity. Öztürk et al [16] also used a pin-on-disc tribometer for friction and wear tests of dry friction composite materials. Their results showed that the coefficient of friction decreased with both a rising slip speed and applied load, but increased with disc temperature up to $300^{\circ} \mathrm{C}$.

It is important to validate the measurements obtained with pin-on-disc with those more representative of friction lining material, whilst in situ within a clutch or brake system. This is often better represented by friction disc test rigs as set out in SAE J661a. Marklund and Larsson [17] and Bezzazi et al [18] showed good comparison between pin-on-disc and friction disc test rig frictional characteristics for clutch lining materials.

This paper presents a 4-degree of freedom torsional dynamics model of the clutch system, incorporating the clutch lining interfacial frictional characteristics with measured coefficient of friction under representative clutch slip speed, applied pressures and surface temperatures, using a pin-on-disc set up. Engine order vibrations in the form of torque fluctuations are also included in the model. Such an approach has not hitherto been reported in literature.

\section{Dynamics Model}

A 4-degrees of freedom lumped parameter model is developed, comprising various inertial components of the clutch assembly (figure 1). One inertial component represents the engine (inertia $I_{1}$ ). The second inertia is that of the coupled flywheel and the friction disc $I_{2}$, simplifying the engagement process to that between the friction disc and the pressure plate $I_{3}$. The vehicle inertia, including the remainder of the drivetrain system is represented by the inertial element, $I_{4}$.

The engine/flywheel and the clutch input are connected through an equivalent shaft of known stiffness and damping. Similarly, the same provision is made for the output part of the clutch and the driveline/vehicle. The shaft connecting the flywheel /engine with the input part of the clutch is representative of the crankshaft. 
Proceedings of the Institution of Mechanical Engineers, Part K: Journal of Multibody Dynamics, May 2017, DOI: 10.1177/1464419317708946 (Accepted Version)

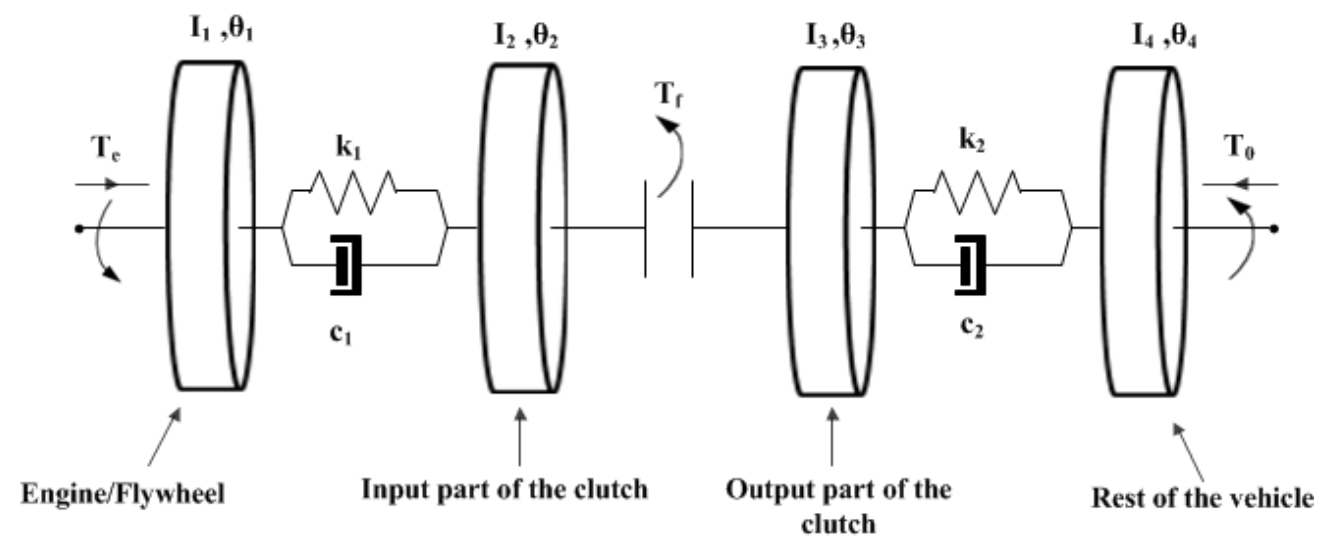

Figure 1: Schematic representation of the dynamic clutch model

The equations of motion for the 4-DOF model are:

$I_{1} \ddot{\theta}_{1}+k_{1}\left(\theta_{1}-\theta_{2}\right)+c_{1}\left(\dot{\theta}_{1}-\dot{\theta}_{2}\right)=T_{e}$

$I_{2} \ddot{\theta}_{2}-k_{1}\left(\theta_{1}-\theta_{2}\right)-c_{1}\left(\dot{\theta}_{1}-\dot{\theta}_{2}\right)=-T_{f}$

$I_{3} \ddot{\theta}_{3}+k_{2}\left(\theta_{3}-\theta_{4}\right)+c_{2}\left(\dot{\theta}_{3}-\dot{\theta}_{4}\right)=T_{f}$

$I_{4} \ddot{\theta}_{4}-k_{2}\left(\theta_{3}-\theta_{4}\right)-c_{2}\left(\dot{\theta}_{3}-\dot{\theta}_{4}\right)=-T_{0}$

where, $T_{e}$ and $T_{f}$ are engine and friction torques respectively and $T_{0}$ is the resistive torque from the driveline. Rewriting equations (1)-(4) under sliding conditions in matrix form:

$[\mathbf{I}] \ddot{\boldsymbol{\theta}}+[\mathbf{C}] \dot{\boldsymbol{\theta}}+[\mathbf{K}] \boldsymbol{\theta}=\mathbf{T}$

where,

$\left[\begin{array}{cccc}I_{1} & 0 & 0 & 0 \\ 0 & I_{2} & 0 & 0 \\ 0 & 0 & I_{3} & 0 \\ 0 & 0 & 0 & I_{4}\end{array}\right] \ddot{\boldsymbol{\theta}}+\left[\begin{array}{cccc}c_{1} & -c_{1} & 0 & 0 \\ -c_{1} & c_{1} & 0 & 0 \\ 0 & 0 & c_{2} & -c_{2} \\ 0 & 0 & -c_{2} & c_{2}\end{array}\right] \dot{\boldsymbol{\theta}}+\left[\begin{array}{cccc}k_{1} & -k_{1} & 0 & 0 \\ -k_{1} & k_{1} & 0 & 0 \\ 0 & 0 & k_{2} & -k_{2} \\ 0 & 0 & -k_{2} & k_{2}\end{array}\right] \boldsymbol{\theta}=\left[\begin{array}{c}T_{e} \\ -T_{f} \\ T_{f} \\ T_{0}\end{array}\right]$

Post engagement the system is modelled as a 3-DOF system (Figure 2). This is because the flywheel/friction disc/pressure plate assembly is clamped (i.e. the stick state).

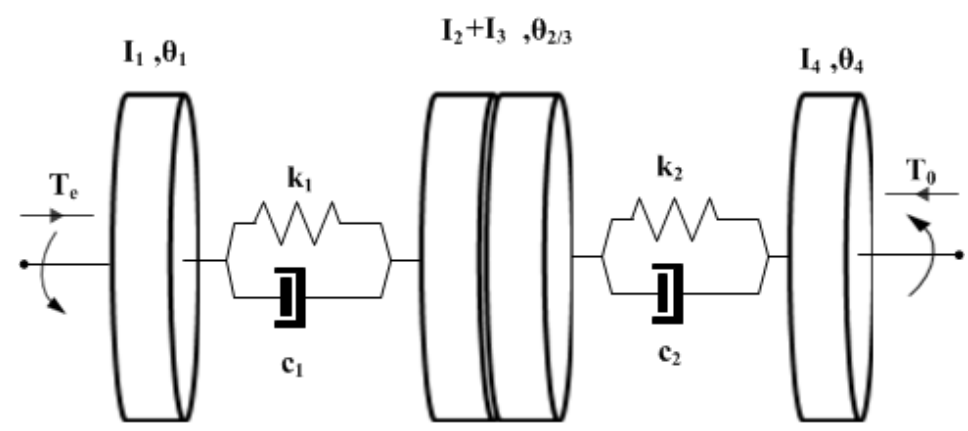


Proceedings of the Institution of Mechanical Engineers, Part K: Journal of Multibody

Dynamics, May 2017, DOI: 10.1177/1464419317708946 (Accepted Version)

Figure 2: Schematic representation of the clamped clutch model

Under clutch clamped conditions, these equations become:

$$
\begin{aligned}
& I_{1} \ddot{\theta}_{1}+k_{1}\left(\theta_{1}-\theta_{2 / 3}\right)+c_{1}\left(\dot{\theta}_{1}-\dot{\theta}_{2 / 3}\right)=T_{e} \\
& \left(I_{2}+I_{3}\right) \ddot{\theta}_{2 / 3}-k_{1}\left(\theta_{1}-\theta_{2 / 3}\right)-c_{1}\left(\dot{\theta}_{1}-\dot{\theta}_{2 / 3}\right)=-k_{2}\left(\theta_{2 / 3}-\theta_{4}\right)-c_{2}\left(\dot{\theta}_{2 / 3}-\dot{\theta}_{4}\right) \\
& I_{4} \ddot{\theta}_{4}-k_{2}\left(\theta_{2 / 3}-\theta_{4}\right)-c_{2}\left(\dot{\theta}_{2 / 3}-\dot{\theta}_{4}\right)=-T_{0}
\end{aligned}
$$

The set of equations for the engaged clutch (stick condition) becomes:

$$
\left[\begin{array}{ccc}
I_{1} & 0 & 0 \\
0 & I_{2}+I_{3} & 0 \\
0 & 0 & I_{4}
\end{array}\right] \ddot{\boldsymbol{\theta}}+\left[\begin{array}{ccc}
c_{1} & -c_{1} & 0 \\
-c_{1} & c_{1}+c_{2} & -c_{2} \\
0 & -c_{2} & c_{2}
\end{array}\right] \dot{\theta}+\left[\begin{array}{ccc}
k_{1} & -k_{1} & 0 \\
-k_{1} & k_{1}+k_{2} & -k_{2} \\
0 & -k_{2} & k_{2}
\end{array}\right] \boldsymbol{\theta}=\left[\begin{array}{c}
T_{e} \\
0 \\
-T_{0}
\end{array}\right]
$$

\subsection{Damping coefficients}

Damping coefficients for the system are calculated, based on the work of Mostofi [19] for structural damping. The damping matrix is expressed in a linear form as a combination of inertias and stiffness matrices:

$$
[\mathbf{C}]=a[\mathbf{J}]+\beta[\mathbf{K}]
$$

where $a$ and $\beta$ are scalar multipliers. The proportional damping method assumes a light internal damping in the system and thereafter the parameter $a$ is set to zero. Accordingly damping matrix is assumed to be proportional to the stiffness matrix. Therefore, equation (11) is transformed into:

$$
[\mathbf{C}]=\beta[\mathbf{K}]
$$

The stiffness proportionality coefficient, $\beta$, is:

$\beta=\frac{2 \zeta_{n}}{\omega_{n}}$

where, $\zeta_{n}$ is the damping ratio of the $n^{\text {th }}$ mode and $\omega_{n}$ is its natural frequency. To calculate the natural frequencies of the system, the equivalent eigenvalue problem needs to be solved and the eigenvectors obtained as:

$$
\left([\mathbf{K}]-\omega^{2}[\mathbf{J}]\right) \boldsymbol{\theta}=0
$$

The driveline system is rather poorly damped [11] with damping ratios in the range 0.01-0.05 [20-21]. In the current study a representative mean value of 0.03 is chosen. 


\subsection{Resistive torque}

In the above model the resisting torque, $T_{0}$, is calculated as the sum of rolling resistance, $F_{\text {rol }}$, and aerodynamic drag, $F_{\text {drag }}$, [22]:

$T_{0}=R_{w}\left(F_{\text {rol }}+F_{\text {drag }}\right)$

where, $R_{w}$ is the laden wheel radius.

Rolling resistance, $F_{\text {rol }}$ depends on the coefficient of rolling resistance, $\mu_{\text {rol }}$ and the vehicle weight, $W_{v}$ :

$F_{\text {rol }}=\mu_{\text {rol }} W_{v}$

The aerodynamic drag is:

$F_{\text {drag }}=\frac{d_{a i r} V^{2} C_{d} A}{2}$

where, $d_{\text {air }}$ is the density of air, $V$ the velocity of the vehicle, $C_{d}$ is the aerodynamic drag coefficient and $A$ is effective vehicle frontal area.

\subsection{Engine torque}

The engine power torque is subject to fluctuations according to the combustion process (4 or 2-strokes) and the engine configuration (number of cylinders and crankshaft flexibility). The resulting vibration superimposed upon steady engine speed yields engine order vibrations [23] which should be included in any practical analysis. Engine harmonics are used to describe the variation of the engine torque with time. Therefore, the engine output torque, $T_{e}$, comprises a mean component, $T_{m}$, and a fluctuating part, $T_{p}$, (unbalanced torque). Therefore, the torque presented by a Fourier series becomes:

$T_{e}=T_{m}+\sum_{n} T_{p n} \sin \left(n \omega_{e} t+\varphi_{p n}\right)$

where, $\omega_{e}=\dot{\theta}_{1}, n$ is the harmonic order of the unbalanced torque, $\omega_{e}$ is the nominal angular velocity of the engine crankshaft, and $\varphi_{p n}$ is the initial phase of the $n^{\text {th }}$ order which for a 4stroke combustion process is [23]: $n=0.5,1,1.5,2,2.5,3 \ldots$. The engine modelled in this analysis is a 4-stroke 4-cylinder 1.81 Litre diesel engine. Engine torque resonance occurs when the $n$th engine order harmonic $\left(n \omega_{e}\right)$ for any harmonic order equates the natural frequency of the piston-connecting rod- crankshaft sub-system, $\omega_{n}$. At such a resonance the engine speed is regarded as a critical speed, $S_{n}^{i}$, at the $i$ th mode shape, defined as:

$S_{n}^{i}=\frac{S_{i}}{n}=\frac{60}{2 \pi} \frac{\omega_{i}}{n}$

For the selected engine that the $n^{\text {th }}$ engine order harmonic is described as: 
$\frac{60}{2 \pi} \frac{\omega_{i}}{s_{\max }} \leq n \leq \frac{60}{2 \pi} \frac{\omega_{i}}{s_{\min }}$

The speed range of interest for the diesel engine studied is 700-3000rpm, with the natural frequency of the system being: $\omega_{n}=77.5 \mathrm{rad} / \mathrm{s}$. Substituting this into equation (20), the critical engine orders are: $n=0.24 \sim 1.06$, hence $n_{1}=0.5$ and $n_{2}=1$. As this is a 4-cylinder 4 -stroke engine, the cylinder firing phase variation is $2 \pi / 4$, so the initial phase for the first order, $\varphi_{p 1}$, is set to zero and the second order, $\varphi_{p 2}$, to $\pi / 2$. The mean component of the torque, $T_{m}$, is assumed to be constant at a value of $300 \mathrm{Nm}$ and the fluctuating parts $T_{n 1}=$ $T_{n 2}=50 \mathrm{Nm}$. Therefore, equation (18) can be rewritten as:

$T_{e}=300+50 \sin \left(0.5 \omega_{e} t\right)+50 \sin \left(\omega_{e} t+\frac{\pi}{2}\right)$

\subsection{Friction torque}

During the clutch engagement different interfacial slip velocities occur between the friction lining and the flywheel and the pressure plate. The sliding of interfaces leads to the generation of friction. The friction torque calculated in the area of an annular surface similar to that of a clutch pad is:

$T_{f}=\iint_{A} \frac{r f}{A} d A=\iint_{A} \frac{r F_{n} \mu}{\pi\left(r_{o}^{2}-r_{i}^{2}\right)} d A=\iint \frac{r F_{n} \mu}{\pi\left(r_{o}^{2}-r_{i}^{2}\right)} r d r d \vartheta=\frac{F_{n} \mu}{\pi\left(r_{o}^{2}-r_{i}^{2}\right)} \int_{r_{i}}^{r_{o}} \int_{0}^{2 \pi} r^{2} d r d \vartheta=$

$\frac{2 F_{n} \mu\left(r_{o}^{3}-r_{i}^{3}\right)}{3\left(r_{o}^{2}-r_{i}^{2}\right)}=\frac{2}{3} R F_{n} \mu$

where, $R=\frac{r_{o}^{3}-r_{i}^{3}}{r_{o}^{2}-r_{i}^{2}}$ is the effective radius of the clutch [5-6], $f$ is friction, $A$ the area of the clutch, $r_{o}$ and $r_{i}$ are the outer and inner radii of the friction lining surface respectively. $\mu$ is the coefficient of friction and $F_{n}$ is the applied normal load (generally termed as clutch clamp load) (Figure 3). This is the typical profile proposed for the normal load in clutch applications $[9,24]$.

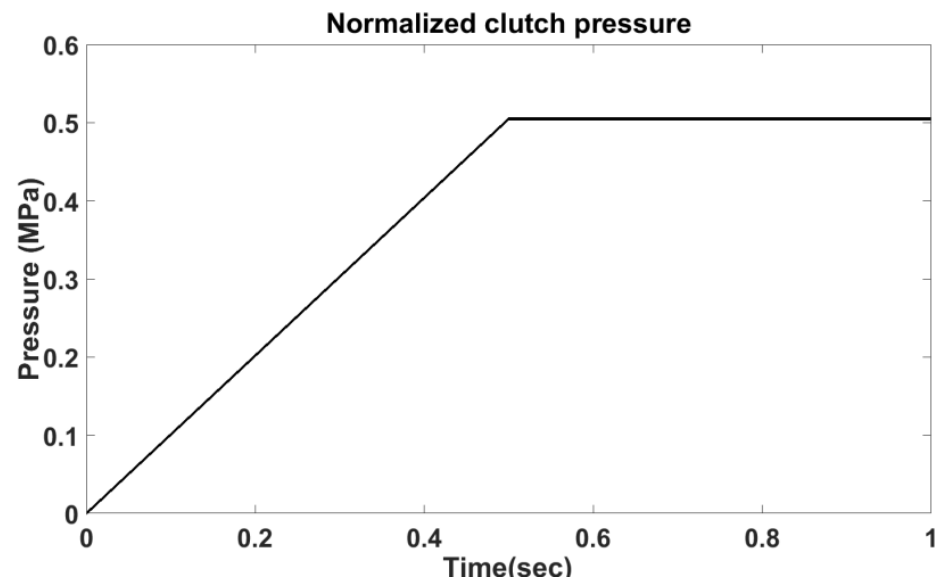

Figure 3: Normalised clutch pressure during clutch engagement 


\subsection{Stick-slip algorithm}

The generated clutch friction torque varies transiently according to the stick-slip oscillatory behaviour during the clutch engagement (take-up) process. This is of course a function of clamp load, contact area and coefficient of friction, which itself is a function of the lining material choice, contact pressure, generated temperature and contact kinematics. Therefore, the coefficient of friction must be determined through experimentation. Under sliding conditions, the kinetic coefficient of friction varies transiently with in situ conditions. Static coefficient of friction occurs at the onset of sliding, post the stiction phase. Under stiction conditions there is clearly no generated friction, thus:

$T_{f}= \begin{cases}\frac{2}{3} R F_{n} \mu & \text { if }\left(\omega_{2}-\omega_{3}\right)>0 \\ -\frac{2}{3} R F_{n} \mu & \text { if }\left(\omega_{2}-\omega_{3}\right)<0 \\ 0 & \text { if }\left(\omega_{2}-\omega_{3}\right)=0\end{cases}$

where, $\omega_{2}=\dot{\theta_{2}}$ and $\omega_{3}=\dot{\theta_{3}}$ are the angular velocities of the clutch disc and the pressure plate respectively. $\mu=0$ under stiction condition and varies transiently with clutch interfacial conditions under slip condition. During the engagement process the coefficient of friction alters until ideally a full clamp load is achieved.

\section{Experimental setup and measurements}

The interfacial coefficient of friction varies according to the lining-type material, surface topography of the contacting pairs, as well as the operating conditions, comprising clamp load, interfacial slip speed and contact temperature. Therefore, for a given lining material, its topography and that of the pressure plate, the variables affecting the kinetic coefficient of friction are the operating conditions. Therefore, it is important to measure the coefficient of friction, using a rig set up under representative vehicle clutch conditions. In this paper an appropriately instrumented pin-on-disc tribometer is used for this purpose.

Pin-on-disc tribometer is a widely used standard apparatus for tribological assessment of material pairs in counterformal contact. Measurements are carried out in line with the standard test procedures set out in ASTM G99 or DIN 50324.

Figure 4 shows the experimental set up comprising a pin-on-disc apparatus. The pin-on-disc comprises a disc, made out of the same stock as the pressure plate and subjected to the same surface treatment (i.e. yielding the same surface topography as a new pressure plate). The disc is rotated by an AC induction motor. The pin is attached to an arm instrumented with a strain gauge rosette, calibrated to measure the tangential applied force, transmitted from the pin-disc contact. Signal conditioning and data acquisition from the strain gauges is carried out using a National Instrument cDAQ-9178 chassis, housing a specialised NI-9237 module with a 4-channel analogue input device with USB PC connectivity.

A square piece of new friction lining material, with precisely measured topography is cut and attached firmly (horizontally) to the pin. This makes contact with the rotating surface of the 
disc. A vertical load is applied onto the pin, resulting in the same contact average (Pascal) pressure as the clamp load variation during the clutch engagement process. The pin contacts the surface of the rotating disc at various track radii in order to obtain representative slip speeds, occurring during the clutch engagement process. Finally, the disc is heated through use of a copper disc cartridge placed underneath the rotating disc, and powered with a three $100 \mathrm{~W}$ heating cartridges. The temperature of the contact is monitored by a K-type thermocouple and maintained steadily by a temperature control unit. Heat is conducted through to the test disc so that its bulk surface temperature can be varied according to different interfacial temperatures under different representative vehicle conditions.

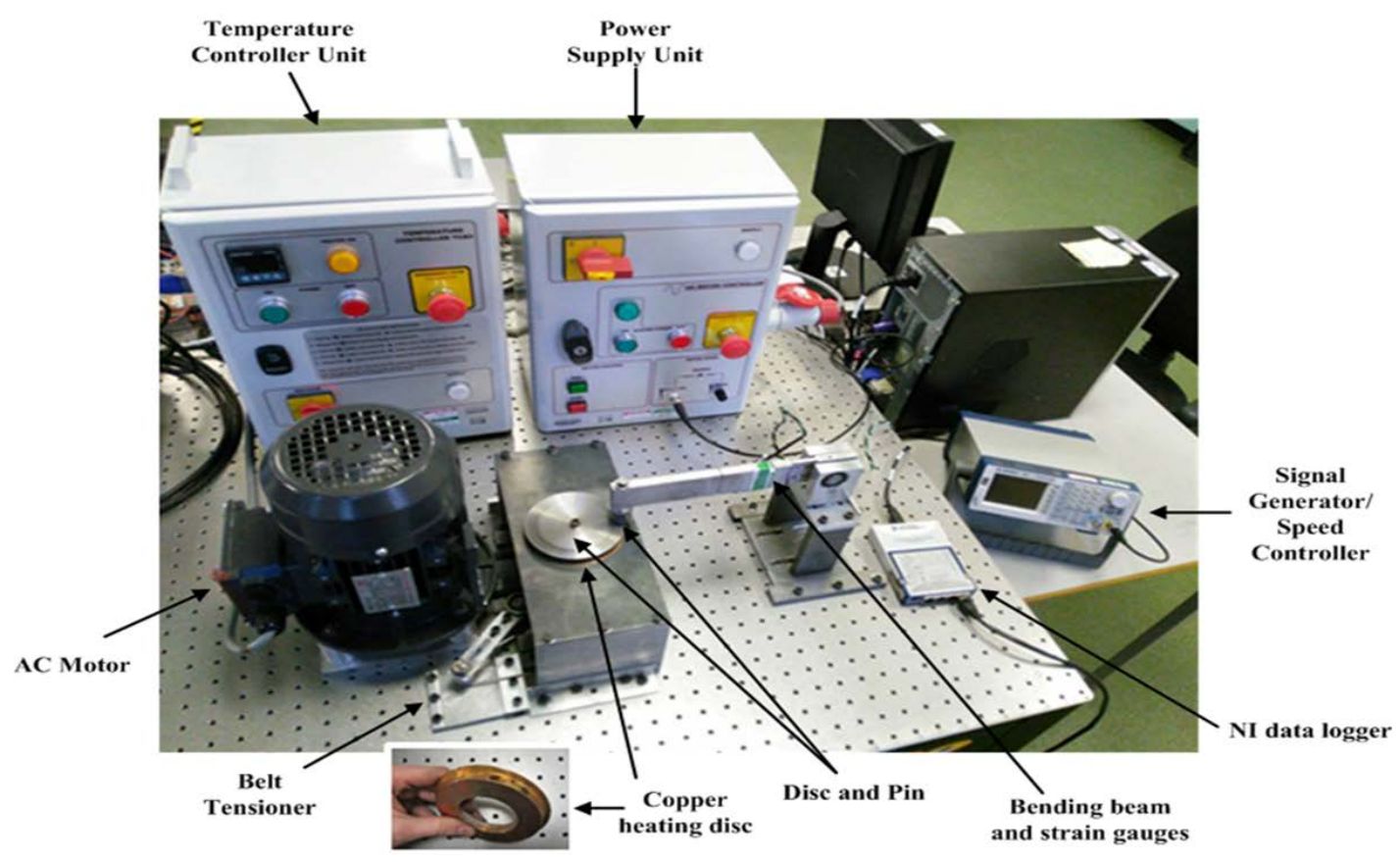

Figure 4: Fully instrumented pin-on-disc rig

National Instruments LabView is used to process the measured friction data during testing and record the same in a spreadsheet-friendly data files for subsequent post-processing and analysis.

\subsection{Test protocol}

In situ measurements of the coefficient of friction tend to be sensitive to surface roughness, waviness and to the presence of surface oxides and any contamination. These factors increase the overall measurement error. To tackle the problem a test protocol is introduced, consisting of a number of surface cleaning steps, and monitoring any changes to the surfaces of the clutch lining and pressure plate samples.

The cleaning of the pressure plate is performed in a three stage chemical cleaning process, following the ASTM G99-05 standard, which recommends cleaning the counterpart surfaces of any grease, cutting fluid residue, debris and other contaminants before each test as these can affect the outcome of the measurements. Surface of the disc/pressure plate is cleaned 
using three different solvents, wiping away their excess residue with a lint free cloth to avoid any contamination. The solvents used are petroleum ether, followed by methanol and finally acetone. After each cleaning session the disc sample is left to dry in air. Post-cleaning, any skin contact with the surface of the disc is avoided. Before any measurement, surface topography of the pressure plate is recorded using a white optical interferometer (Alicona with nominal vertical measurement resolution of $1 \mathrm{~nm}$ and lateral horizontal sensitivity of $0.174 \mu \mathrm{m})$. This determines any wear of the surfaces caused by prior tests. In such cases, the disc is reground to the same overall surface topography, determined by statistical surface roughness parameters. ASTM G115-10 standard suggests each test condition should run for a predetermined sliding distance in order to allow for direct comparison of results. In the current study a distance of $300 \mathrm{~m}$ is chosen.

For every friction measurement a new clutch sample is used in order to ensure consistent and repeatable conditions. After testing, the disc is scanned to monitor any changes to its surface topography as recommended by ATSM G163-10 standard (as stated above). This procedure is repeated for each test. The same procedure is also applied to friction lining samples. ASTM G115-10 standard also gives further guidance on a number of potential sources of errors/inconsistencies, which are fully complied with in this study.

\subsection{Test conditions}

The test conditions are chosen to represent the actual clutch conditions in terms of applied contact pressure, sliding velocity and temperature during the clutch engagement process. These are supplied by the clutch manufacturer for clamp load variation. Additionally, it is assumed that the sliding velocity would reduce almost linearly with respect to the slipping time, $t_{s}$. This is expressed as:

$\omega_{s}=\omega_{o}\left(1-\frac{t}{t_{s}}\right)$

The time for full clutch engagement, reaching the maximum designed clamp load is 0.5 seconds for the investigated system. Equation (24) can be adjusted to simulate different clutch actuation times by varying $t_{s}$. Note that hurried clutch actuation results in exacerbated stick-slip vibration, known as clutch take-up judder [2, 5-6, 8]. Based on these assumptions a table of combinations of contact pressures and sliding velocities is created (Table 1) for the real clutch and the equivalent for pin-on-disc conditions. For clutch clamp load representation the average contact pressure of the disc-pin contact equates the average pressure of the clutch interfacial contact. This is the instantaneous clamp load over the total active friction disc pad area. Therefore, no misalignment or thermal distortion of the clutch friction disc is assumed. The interfacial clutch surface sliding speed is achieved by the variation of disc speed or the contact track radius.

Table 1: Comparison of clutch engagement conditions with the equivalent pin-on-disc tests

\begin{tabular}{|c|c|c|c|c|}
\hline \multicolumn{2}{|c|}{ Equivalent pin-on-disc condition } & \multicolumn{2}{c|}{ Clutch condition } \\
\hline Test time & Speed & Load & Clamp load & Flywheel speed \\
\hline
\end{tabular}


Proceedings of the Institution of Mechanical Engineers, Part K: Journal of Multibody Dynamics, May 2017, DOI: 10.1177/1464419317708946 (Accepted Version)

\begin{tabular}{|c|c|c|c|c|}
\hline (s) & $(\mathrm{m} / \mathrm{s}) /(\mathbf{R P M})$ & (kg) & $(\mathbf{N})$ & $(\mathrm{m} / \mathrm{s})$ \\
\hline 30 & $10.1 / 2412$ & 0.21 & 400 & 10.1 \\
\hline 37 & 8.3 / 1972 & 0.48 & 900 & 8.3 \\
\hline 55 & $5.5 / 1311$ & 1.12 & 2250 & 5.5 \\
\hline 82 & $3.7 / 878$ & 2.00 & 3750 & 3.7 \\
\hline 110 & $2.7 / 656$ & 2.66 & 5000 & 2.7 \\
\hline 210 & $1.4 / 342$ & 3.72 & 7000 & 1.4 \\
\hline 1257 & $0.2 / 57$ & 5.32 & 10000 & 0.2 \\
\hline
\end{tabular}

The initial flywheel speed, $\omega_{o}$, is at the idle engine speed transition to first gear engagement at the angular velocity of $100 \mathrm{rad} / \mathrm{s}$. The selected temperature range is based on the manufacturer's recommendations for optimum clutch lining performance.

\subsection{Experimental measurements}

Measurements are performed to determine the clutch lining frictional characteristics under various operating conditions. Figure 5 shows the variation of coefficient of friction with interfacial sliding velocity at different disc bulk temperatures. It should be noted that the contact temperature (flash temperature) would be in excess of the measured bulk temperature. However, this is a good indication of the clutch lining material performance at nominal working temperatures of the clutch. A comprehensive carpet-map plot of coefficient of friction variation with interfacial slip speed, clamp load variation and bulk surface temperature of the representative pressure plate disc is provided by Humphrey et al [25]. Those presented here are for the specific the same dry clutch under the simulated manoeuvre.

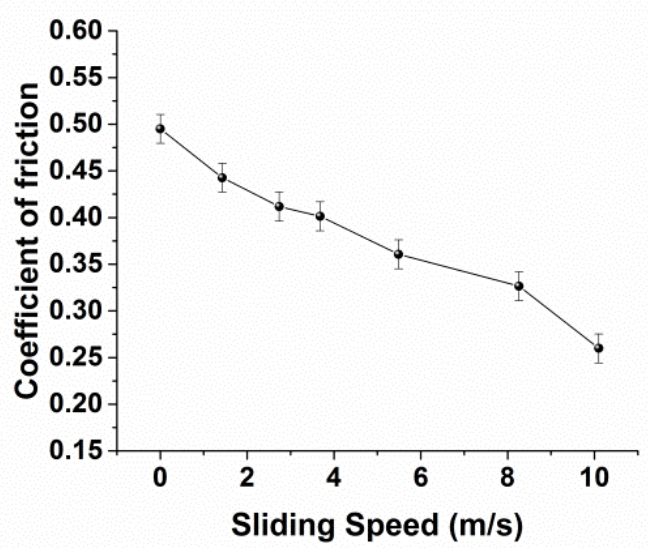

(a)

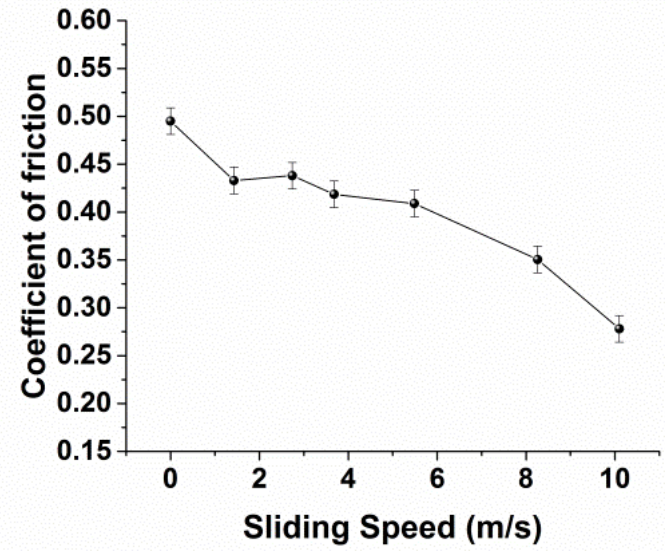

(b) 


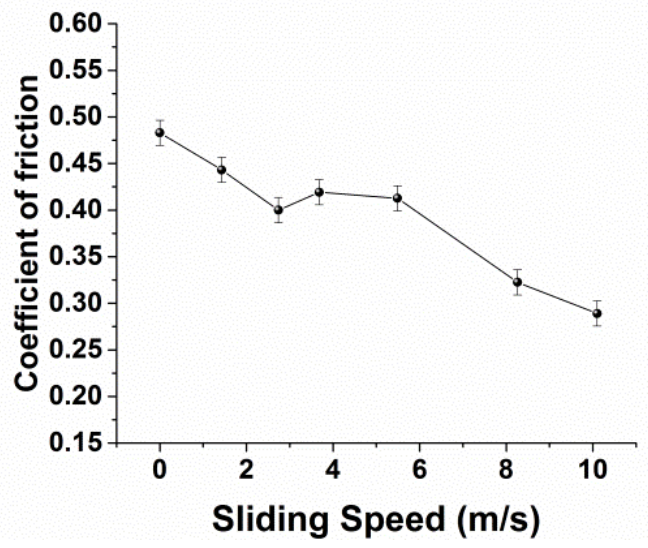

(c)

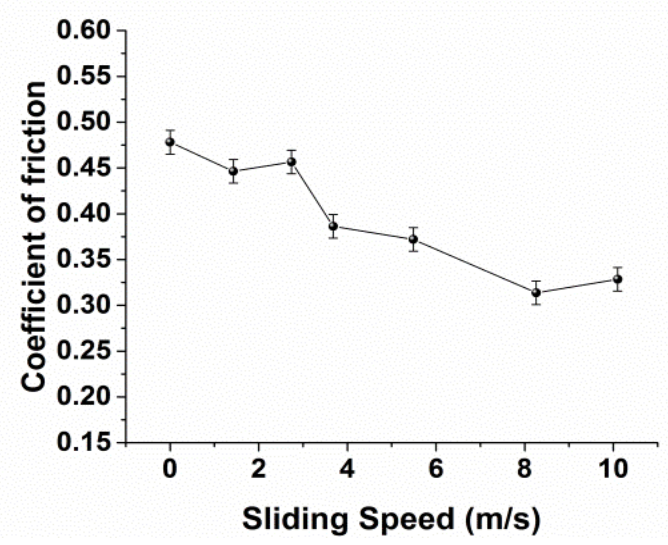

(d)

Figure 5: Coefficient of friction variation with interfacial slip speed for various bulk disc temperatures: (a) $20^{\circ} \mathrm{C}$, (b) $40^{\circ} \mathrm{C}$, (c) $60^{\circ} \mathrm{C}$ and (d) $90^{\circ} \mathrm{C}$

The results in figure 5 are indicative of the various stages of the engagement process. As the two contacting surfaces converge, the initial temperature is considered to be $20^{\circ} \mathrm{C}$ as shown in figure 5(a). However, as the engagement proceeds further, the temperature in the clutch contact rapidly rises. The results in Figures 5(b) to (d) show the variation of coefficient of friction at other clutch operating temperatures, which are typical of temperatures of the clutch system under consideration.

Measured coefficients of friction are listed in Table 2 for various stages of the engagement process as the slip speed alters with increasing levels of clamp load to the final fully locked state. This is a condensed version of specifically extracted results for the conditions of the clutch dynamics, encountered in the current analysis. A regression analysis is used to represent the data measured data from Table 2.

Table 2: Variation of coefficient of friction with slip speed, $v$ at different temperatures

\begin{tabular}{cc}
\hline Temperature & Coefficient of friction extrapolated equation $(\boldsymbol{\mu})$ \\
\hline $\mathbf{2 0}^{\circ} \mathrm{C}$ & $0.48-0.0210 v$ \\
$\mathbf{4 0}^{\circ} \mathrm{C}$ & $0.49-0.0191 v$ \\
$\mathbf{6 0}^{\circ} \mathrm{C}$ & $0.48-0.0178 v$ \\
$\mathbf{9 0}^{\circ} \mathrm{C}$ & $0.47-0.0167 v$ \\
\hline
\end{tabular}

In the absence of any fundamental theory for description of frictional behaviour of the clutch material based on sliding speed, temperature etc., the simplest and widely accepted approach is the use a linear relationship. In all such formulae in the literature (e.g. [5-7]) the form: $\mu=\mu_{s}-m v$ is employed, where the intercept $\mu_{s}$ is the static coefficient of friction and $m$ is the gradient of kinetic coefficient of friction variation with slip speed. Two important observations can be made. Firstly, the static coefficient of friction hardly alters with temperature for a new (fresh) friction lining material. Of course, subsequently this alters with wear. Secondly, the slope of kinetic coefficient of friction is negative with slip speed under 
Proceedings of the Institution of Mechanical Engineers, Part K: Journal of Multibody

Dynamics, May 2017, DOI: 10.1177/1464419317708946 (Accepted Version)

all conditions. According to the findings of Centea et al [5-6] a negative slope indicates a propensity to judder. However, as they have shown take-up judder is only discernible with significant torsional oscillations of the clutch system.

\section{Numerical Predictions}

The system of the differential equations corresponding to the sliding condition (equations (1)(4)) and that for the fully clamped condition (equations (5)-(7)) are solved numerically using the ode45 solver in MATLAB. The simulation corresponds to an engine speed of 960rpm, or an initial angular velocity of $100 \mathrm{rad} / \mathrm{s}$. This is the idle engine speed at the instance of clutch engagement. During the engagement process, the engine speed drops (for the inertial components $I_{1}$ and $\left.I_{2}\right)$ and the speed of the driven inertial components $\left(I_{3}\right.$ and $\left.I_{4}\right)$ increases, ideally to reach fully clutch clamped condition. The experimentally measured coefficients of friction (Table 2) are used to determine the instantaneous friction torque, $T_{f}$, during the engagement transient process as the slip speed alters with an increasing clamp load and at different assumed aforementioned bulk clutch disc temperatures. All the model parameters are listed in Table 3.

Table 3: Model parameters

\begin{tabular}{llc}
\hline Parameters & Values & Unit \\
\hline Torsional inertia, $\boldsymbol{I}_{\mathbf{1}}$ & 1 & $\mathrm{kgm}^{2}$ \\
\hline Torsional Inertia, $\boldsymbol{I}_{\mathbf{2}}$ & 0.3 & $\mathrm{kgm}^{2}$ \\
\hline Torsional Inertia, $\boldsymbol{I}_{\mathbf{3}}$ & 0.015 & $\mathrm{kgm}^{2}$ \\
\hline Torsional Inertia, $\boldsymbol{I}_{\boldsymbol{4}}$ & 6 & $\mathrm{kgm}^{2}$ \\
\hline Damping coefficient, $\boldsymbol{c}_{\mathbf{1}}$ & 15 & $\mathrm{Nms} / \mathrm{rad}$ \\
\hline Damping coefficient, $\boldsymbol{c}_{\mathbf{2}}$ & 4 & $\mathrm{Nms} / \mathrm{rad}$ \\
\hline Stiffness coefficient, $\boldsymbol{k}_{\mathbf{1}}$ & 20000 & $\mathrm{Nm} / \mathrm{rad}$ \\
\hline Stiffness coefficient, $\boldsymbol{k}_{\mathbf{2}}$ & 5000 & $\mathrm{Nm} / \mathrm{rad}$ \\
\hline Wheel radius, $\boldsymbol{R}_{\boldsymbol{w}}$ & 0.34 & $\mathrm{M}$ \\
\hline Vehicle mass, $\boldsymbol{m}_{\boldsymbol{v}}$ & 2500 & $\mathrm{Kg}$ \\
\hline Coefficient of rolling resistance, $\boldsymbol{\mu}_{\boldsymbol{r o l}}$ & 0.015 & - \\
\hline Density of air, $\boldsymbol{d}_{\boldsymbol{a i r}}$ & 1.2922 & $\mathrm{~kg} / \mathrm{m}^{3}$ \\
\hline Effective vehicle frontal area, $\boldsymbol{A}$ & 2.8 & $\mathrm{~m}{ }^{2}$ \\
\hline Aerodynamic drag coefficient, $\boldsymbol{C}_{\boldsymbol{d}}$ & 0.37 & - \\
\hline
\end{tabular}




\begin{tabular}{lcc}
\hline Inner radius of clutch, $\boldsymbol{r}_{\boldsymbol{i}}$ & 0.0925 & $\mathrm{M}$ \\
Outer radius of clutch, $\boldsymbol{r}_{\boldsymbol{o}}$ & 0.135 & $\mathrm{M}$ \\
\hline
\end{tabular}

Figure 6 shows the variation of angular velocities of the engine/flywheel/friction disc assembly (driver in this model), and the pressure plate and vehicle inertia (the driven) during the process of clutch engagement. The oscillations prior to the take-up are due to the stickslip oscillations of the driven inertia as the result of instantaneous changes in the kinetic coefficient of friction. The oscillations reduce significantly with an increasing clutch surface temperature. This is in line with experience of an increased take-up judder response under cold vehicle conditions. Post clutch take-up judder (with a fully clamped clutch), the angular velocities of the driving and driven inertias coincide, with smaller oscillations as the result of transmitted engine order vibrations.

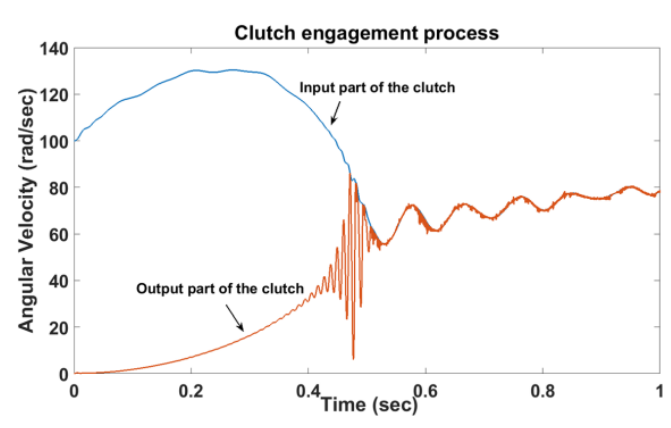

(a)

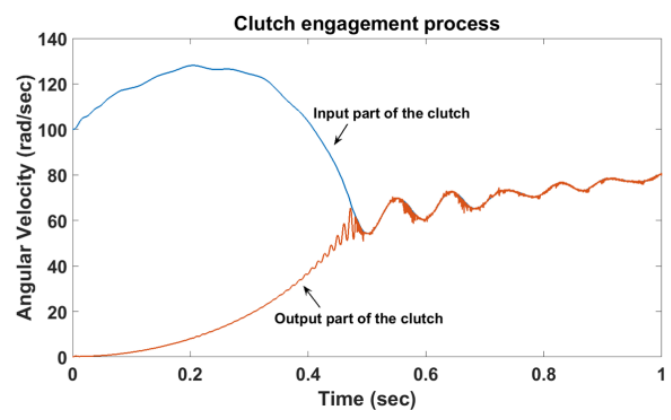

(c)

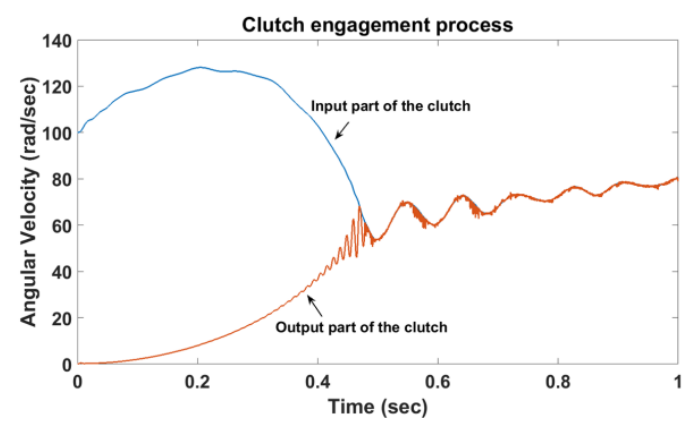

(b)

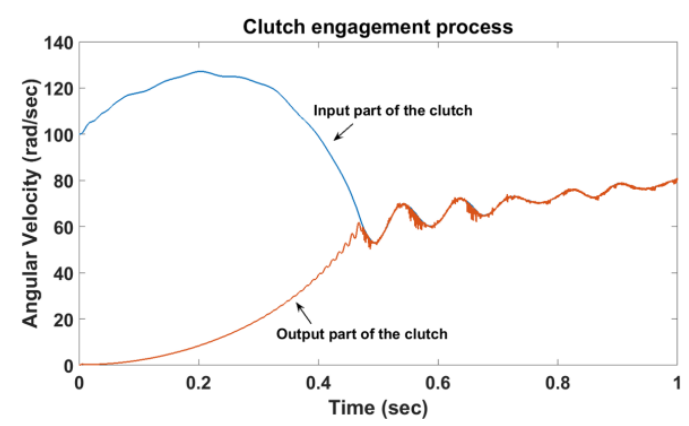

(d)

Figure 6: Clutch engagement process for coefficient of friction of four different temperatures: (a) $20^{\circ} \mathrm{C}$, (b) $40^{\circ} \mathrm{C}$, (c) $60^{\circ} \mathrm{C}$ and (d) $90^{\circ} \mathrm{C}$

The duration of clutch engagement is approximately 0.55s (time to reach full clamp load with full release of the clutch pedal). If the driver releases the clutch in a shorter period (hurried clutch pedal release), full clamp load is not achieved, resulting in clutch judder as shown by Centea et al [5-6]. All the simulation carried out follow the recommended clutch pedal movement for the simulated vehicle. 
Proceedings of the Institution of Mechanical Engineers, Part K: Journal of Multibody

Dynamics, May 2017, DOI: 10.1177/1464419317708946 (Accepted Version)

There is lower frequency content with smaller amplitudes of oscillation than those can be observed in figure 6. Therefore, to observe the broader band response of the system during the engagement process a time-frequency analysis is the most appropriate. For this purpose continuous wavelet transform (CWT) is carried out in order to ascertain the transient spectral response during the engagement process. The function used for the CWT is:

$W_{\psi}(a, b ; f(t), \psi)=\int_{-\infty}^{\infty} f(t) \frac{1}{\sqrt{a}} \psi^{*}\left(\frac{t-b}{a}\right) d t$

where, $\psi$ is the mother wavelet and $*$ denotes the complex conjugate of the function. $a$ is the wavelet scale parameter, $b$ the position parameter and $f(t)$ is the analysed data series. The mother wavelet used in this analysis is the Morlet or Gabor wavelet function:

$\psi(\eta)=\pi^{-(1 / 4)} e^{i m \eta} e^{-\eta^{2} / 2}$

where, $m$ is the wavenumber and $\eta$ is a non-dimensional time parameter. The input parameters are $m$ and $b$ which in this case are 8 and 35 respectively.

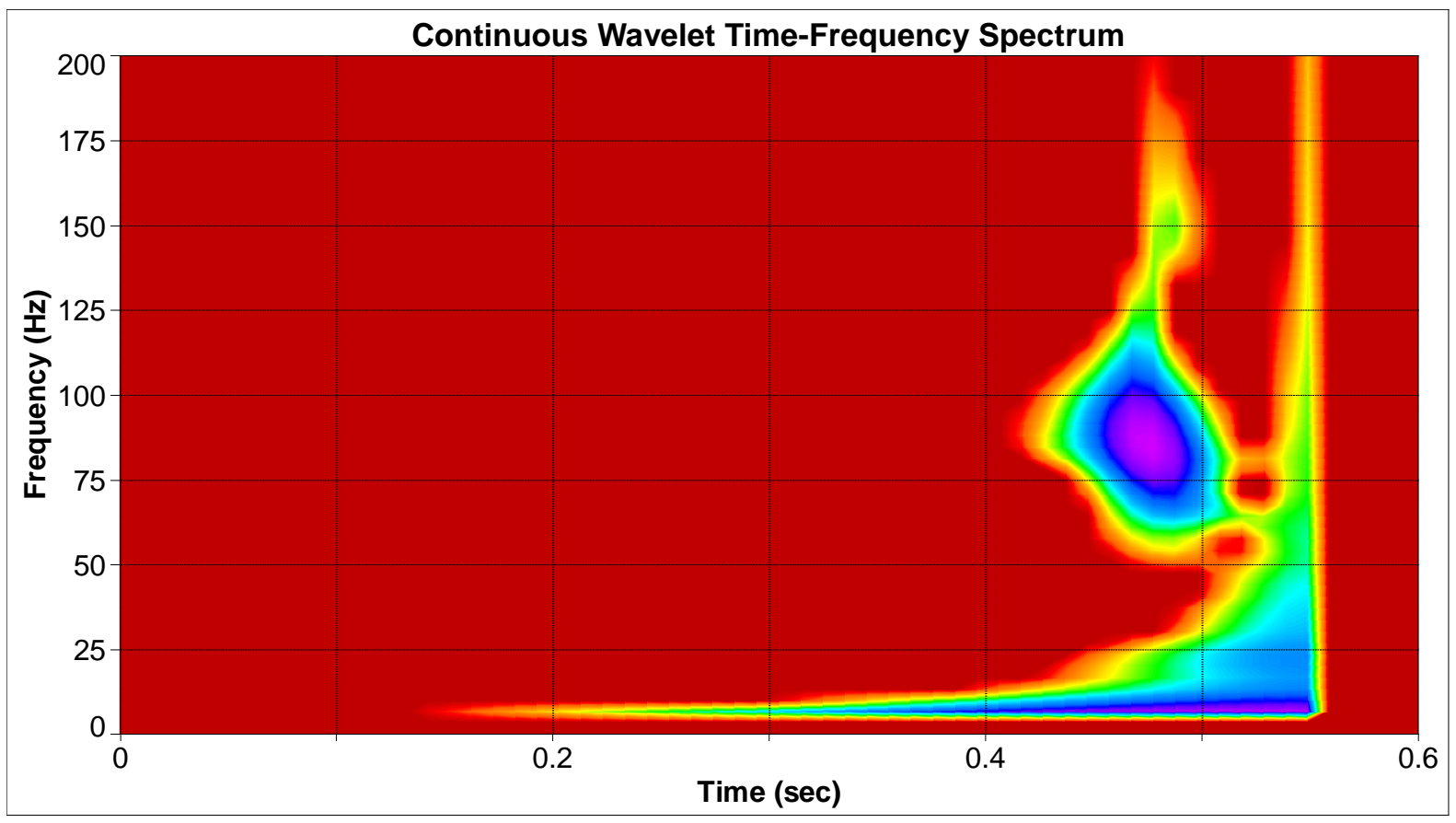

(a) 


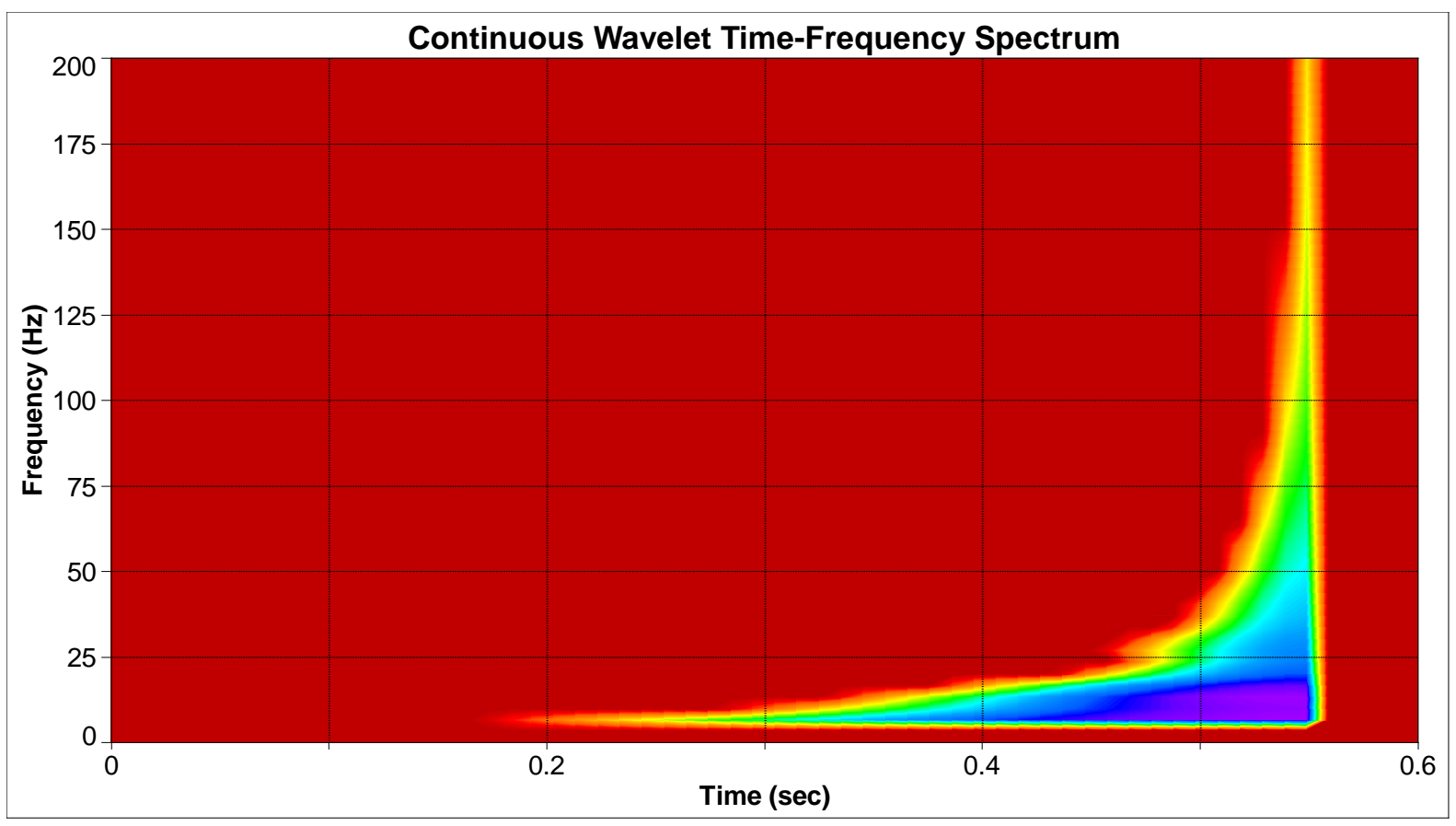

(b)

Figure 7: Continuous wavelet spectrum of the torsional vibrations during clutch engagement for two temperatures: (a) $20^{\circ} \mathrm{C}$ and (b) $90^{\circ} \mathrm{C}$

Figure 7 shows the CWT of the oscillations prior to the fully clamped clutch at 0.55 s. Firstly, it can be seen that the amplitude of torsional vibrations reduce with increased bulk surface temperature of the clutch. Secondly, an interesting observation can be made, indicating that unlike the widely reported (predicted or measured) spectral content of judder being in the range $5-20 \mathrm{~Hz}$, there is a broader range of frequencies, particularly at the lower clutch surface temperatures. At the normal steady state clutch surface temperature of $90^{\circ} \mathrm{C}$, the spectrum of vibration is dominated by the frequency range below $25 \mathrm{~Hz}$. At the low surface temperature of $20^{\circ} \mathrm{C}$ there are momentary sharp oscillations at higher frequencies as well. These are discerned poignantly by the driver under cold vehicle start and particularly at partial clamp load (also observed in figure 6(a)). In actual application, it is expected that the cold contact conditions is rapidly replaced by warmer contact conditions due to a sharp rise in contact temperature as a result of friction. Thermal analysis of the clutch assembly will provide a further insight into the nature of temperature variations in the clutch contact.

An important point to note is that the driver discerns the clutch judder response due to fore and aft motion of the vehicle. This is because of the coupling between the torsional oscillations of the clutch and the axial movements of the powertrain system. Not all the torsional oscillation frequencies couple with the fore and aft motion. In particular, the higher stick-slip interfacial oscillations do not usually transmit to the fore and aft motions, which occur at lower carrier frequencies, because of larger inertial contributions. However, the current model does not include the longitudinal degree of freedom to note this point. Centea et al [5-6] show this with a more complex constrained multi-body dynamic analysis. 


\section{Conclusions}

The paper presents a 4-degree of freedom torsional dynamic model for the investigation of clutch take-up judder phenomenon. The interfacial friction of the clutch lining material in interactions with the surface of pressure plate is obtained under various bulk surface temperatures and with clutch clamp load variation.

The results for the measured coefficient of friction for the clutch lining material show the importance of clutch surface temperature. This is in addition to the already established understanding of the dependency of frictional characteristics on both sliding speed and normal contact load.

The resistive forces on the vehicle during clutch actuation are also included to represent realistic vehicle conditions. The input engine torque, including its unbalanced response due to engine order oscillations are also included in the analysis. Therefore, a comprehensive analysis, representative of various vehicle conditions is carried out.

The outcome of the dynamic model can qualitatively predict the frequencies associated with the judder phenomenon. Since the result for coefficient of friction used in the dynamics model are a function of speed, load and temperature, a direct link can be established between the observed frequencies and the state of tribological clutch contact conditions.

The results show the inherent nature of judder phenomenon with a greater propensity to stickslip variations at lower bulk clutch face temperatures. It also shows the transient broad-band spectral content at lower clutch face temperatures during the take-up engagement.

The outcome of this study points to the necessity for a more detailed dynamic model including interactions in the drivetrain, thus improving the understanding of the judder phenomenon.

\section{Acknowledgements}

The authors would like to thank Ford motor company for the technical support extended to this research.

\section{References}

[1]- Drexl, H. J., “Clutch judder-causes and counter measures”, Proc. Tech. Conf. SITEV, 1990, 90, pp. 7-46.

[2]- Rahnejat, H., Theodossiades, S., Kelly, P. and Menday, M.T., "Drivetrain noise, vibration, and harshness”, Encyclopedia of Automotive Engineering, John Wiley, 2015.

[3]- Jarvis, R. P. and Mills, B., "Vibrations induced by dry friction”, Proc. IMechE, 1963-4, 178(32), pp. 847-866. 
Proceedings of the Institution of Mechanical Engineers, Part K: Journal of Multibody

Dynamics, May 2017, DOI: 10.1177/1464419317708946 (Accepted Version)

[4]- Berglund, K., Marklund, P., Lundh, H. and Larsson, R., "Prediction of driveline vibrations caused by ageing the limited slip coupling”, Proc. IMechE, Part D: J. Automobile Engineering, 2016, 230(12), pp. 1687-1698.

[5]- Centea, D., Rahnejat, H. and Menday, M.T., “Non-linear multi-body dynamic analysis for the study of clutch torsional vibrations (judder)", Applied Mathematical Modelling, 2001, 25(3), pp.177-192.

[6]- Centea, D., Rahnejat, H. and Menday, M.T., “The influence of the interface coefficient of friction upon the propensity to judder in automotive clutches”, Proc.IMechE, Part D: J. Automobile Engineering, 1999, 213(3), pp.245-258.

[7]- Crowther, A., Zhang, N., Liu, D.K. and Jeyakumaran, J.K., “Analysis and simulation of clutch engagement judder and stick-slip in automotive powertrain systems", Proc. IMechE, Part D: J. Automobile Engineering, 2004, 218(12), pp. 1427-1446.

[8]- Menday, M.T. and Rahnejat, H., "Friction lining characteristics and the clutch take up judder phenomenon with manual transmission”, IN: Rahnejat, H. (ed). Tribology and Dynamics of Engine and Powertrain: Fundamentals, Applications and Future Trends, Woodhead Publishing Ltd, Cambridge, 2010, pp. 680 - 702

[9]- Yang, L.K., Li, H.Y., Ahmadian, M. and Ma, B., “Analysis of the influence of engine torque excitation on clutch judder", J. Vibration and Control, 2015, DOI: 1077546315582291.

[10]- Rabeih, E.M. and Crolla, D.A., "Intelligent control of clutch judder and shunt phenomena in vehicle drivelines”, Int. J. Vehicle Design, 1996, 17(3), pp. 318-332.

[11]- Farshidianfar, A., Ebrahimi, M., Rahnejat, H., Menday, M.T. and Moavenian, M., "Optimization of the high-frequency torsional vibration of vehicle driveline systems using genetic algorithms", Proc. IMechE, Part K: J. Multi-body Dynamics, 2002, 216(3), pp. 249262.

[12]- Jacobsson, H., “Aspects of disc brake judder”, Proc. IMechE, Part D: J. Automobile Engineering, 2003, 217(6), pp.419-430.

[13]- Panier, S., Dufrénoy, P. and Weichert, D., “An experimental investigation of hot spots in railway disc brakes”, Wear, 2004, 256(7-8), pp.764-773.

[14]- Graf, M. and Ostermeyer, G.P., "Efficient computation of thermoelastic instabilities in the presence of wear”, Wear, 2014, 312(1-2), pp.11-20.

[15]- Ost, W., De Baets, P. and Degrieck, J., "The tribological behaviour of paper friction plates for wet clutch application investigated on SAE\#II and pin-on-disk test rigs”, Wear, 2001, 249(5-6), pp.361-371.

[16]- Öztürk, B., Arslan, F. and Öztürk, S., "Hot wear properties of ceramic and basalt fiber reinforced hybrid friction materials”, Tribology International, 2007, 40(1), pp.37-48. 
Proceedings of the Institution of Mechanical Engineers, Part K: Journal of Multibody

Dynamics, May 2017, DOI: 10.1177/1464419317708946 (Accepted Version)

[17]- Marklund, P. and Larsson, R., "Wet clutch friction characteristics obtained from simplified pin on disc test”, Tribology International, 2008, 41(9-10), pp.824-830.

[18]- Bezzazi, M., Khamlichi, A., Jabbouri, A., Reis, P. and Davim, J.P., "Experimental characterization of frictional behaviour of clutch facings using Pin-on-disk machine”, Materials \& design, 2007, 28(7), pp. 2148-2153.

[19]- Mostofi, A., "The Incorporation of Damping in Lumped-parameter Modelling Techniques", Proc. IMechE, Part K: J. Multi-body Dynamics, 1999, 213, pp.11-17.

[20]- Crowther, A.R. and Zhang, N., 2005 "Torsional finite elements and nonlinear numerical modelling in vehicle powertrain dynamics”, Journal of Sound and Vibration, 284(3), pp.825-849.

[21]- Bingham, P., Theodossiades, S., Saunders, T., Grant, E. and Daubney, R., 2016 “A study on automotive drivetrain transient response to 'clutch abuse'events", Proceedings of the Institution of Mechanical Engineers, Part D: Journal of Automobile Engineering, 230(10), pp.1403-1416.

[22]- Gillespie, T.D., "Fundamentals of vehicle dynamics”, Society of Automotive Engineers, Warrendale, PA, USA, 1992.

[23]- Hestermann, D.C. and Stone, B.J., 1994, "Secondary inertia effects in the torsional vibration of reciprocating engines”, Proc. IMechE, Part C: J. Mech. Eng. Sci., 208, pp. 11-15

[24]- Wang, Y., Kraska, M. and Ortmann, W., 2001, "Dynamic modeling of a variable force solenoid and a clutch for hydraulic control in vehicle transmission system”, Proceedings of the 2001, Vol. 3, pp. 1789-1793, IEEE.

[25]- Humphrey, E., Gkinis, T., Morris, N., Leighton, M., Rahmani, R. and Rahnejat, H., " Clutch lining frictional characteristics under thermal tribodynamic conditions", 3rd Biennial Int. Conf. on Powertrain Modelling and Control (PMC 2016), Loughborough University, 7-9th Sept, 2016 